\title{
Study on the Efficiency of the Synchronous Alkali-ultrasonic Pretreatment of the Low Organic Matter Sludge and its Influence on the Microbial Population in the Anaerobic Digestion System
}

\author{
Shihu Liu*(**), Lei He*, Pengcheng Zhao*, Xuejie He*, Xingxing Zhuo* and Jian Zhou*† \\ *Key Laboratory of the Three Gorges Reservoir's Eco-Environments, Chongqing University, Chongqing, 400045, \\ P.R. China \\ **Chongqing Drainage Co. Ltd, Chongqing, 400045, P.R. China \\ †Corresponding author: Jian Zhou; liushihucq@126.com
}

Nat. Env. \& Poll. Tech. Website: www.neptjournal.com

Received: 10-12-2019

Revised: $03-01-2020$

Accepted: 28-03-2020

Key Words:

Sludge

Alkali treatment

Ultrasound treatment

Anaerobic digestion

Archaea group

\begin{abstract}
To solve the problem of the low anaerobic digestion efficiency of the minimal organic matter sludge, the study proposes the synchronous alkali-ultrasonic pretreatment technology of the low organic sludge. The research results show that the collaboration between alkali and ultrasonic has significant effects on pretreatment efficiency. The pretreatment efficiency of the sorts is as follows: synchronous alkaliultrasonic treatment $>$ alkali-ultrasonic stepwise treatment $>$ ultrasonic-alkali stepwise treatment > ultrasonic treatment $>$ alkali treatment. The synchronous alkali-ultrasonic treatment system has strong processing effectiveness. Compared with the control group (the raw sludge), the concentrations of the supernatant SCOD and VFAs of the low organic matter sludge after the pretreatment increases by 15.4 times and 59.64 times respectively, and the supernatant that is easily biodegradable organic matter increase by $19.1 \%$. The gas production after alkali-ultrasonic synchronous pretreatment of the anaerobic digestion system of the sludge increases $58 \%$ higher than the control group (without pretreatment ). The results of the high-throughput sequencing of 16S rRNA in the anaerobic digestion system of the sludge, at the genus level, show that the dominant functional bacteria in the system mainly includes vadinHA17, Peptoclostridium, Peptostreptococcaceae, Tissierella, Syntrophomonas, Synergistaceae and Aminobacterium. The dominant functional bacteria genera in the systematic archaea group mainly include Methanosaeta (70.33\%), Unclassified (2.74\%), Methanosarcina (15.49\%), Methanobacterium (5.31\%), Methanospirillum (2.18\%), ARC26 (1.04\%), Methanobrevibacter (1.62\%). The abundance of functional bacteria at the genus level was higher than that in the control group.
\end{abstract}

\section{INTRODUCTION}

The anaerobic digestion of the surplus sludge in urban sewage treatment plants is considered to be the most effective way for sludge treatment and recycling due to its potential for energy recovery and environmental hazards reduction. The biogas generated through anaerobic digestion can be used to generate electricity, which can offset about $25 \% \sim 30 \%$ of the electricity consumption in the whole sewage treatment plant (Carrere et al. 2010). At present, the sewage treatment scale of the urban sewage plants in China has been up to 210 million $\mathrm{m}^{3} / \mathrm{d}$, and the sludge treatment scale has reached 37000 $\mathrm{t} / \mathrm{d}$. However, the organic content of the sludge (VSS/TSS) in China is usually 20\% 50\%, far lower than 70\% 80\% in developed countries (He et al. 2007), and the sand content in the sludge is $30 \% \sim 46 \%$. The low organic sludge has severely restricted the application and development of the sludge anaerobic digestion technology.
Sludge pretreatment by alkali technology, namely dosing alkaline reagents, could induce the depolymerization of the refractory organic in the sludge through the solvation and saponification of reagents and facilitate the enzymatic reaction with the extracellular hydrolase. Moreover, it provides additional alkalinity for the anaerobic digestion system and improves the activity of the methane bacteria and the stability of the anaerobic digestion system. $\mathrm{NaOH}$ is considered to be the most effective reagent for the cell decomposition and sludge dissolution (Jang \& Ahn 2013). The low pH environment can only destroy the EPS but not the cell structure in the sludge. The high $\mathrm{pH}$ environment can destroy the cell wall and produce the saponification reaction with the lipids contained in the cell membrane and dissolve it. When the $\mathrm{pH}$ is 12 , the COD dissolution rate can reach $43.5 \%$, and the rise in the rate of SCOD slows down when the $\mathrm{pH}$ continues to increase (Delgèns et al. 2000). However, the excessive high metal ions will inhibit microbial metabolism and reduce the 
methane production capacity of the system ( $\mathrm{Li}$ et al. 2012). Generally, it may be solved by coordination with other methods. For example, when the temperature is raised to $140^{\circ} \mathrm{C}$ ( $\mathrm{pH}=12$, contact $30 \mathrm{~min}$ ), the COD dissolution rate can be increased by $51 \%$. However, the thermo-alkali technology has some problems such as high energy consumption and equipment corrosion.

The ultrasonic technology for sludge pretreatment mainly uses the cavitation effect of the low-frequency ultrasonic wave to generate resonance in the sludge to form the cavitation bubbles. The strong jet flow formed by the burst of the bubbles creates a huge shear force in the liquid to destroy the flocs and microbial cells (Neis et al. 2000). The higher frequency ultrasonic generates a large number of hydroxyl radicals, which can enhance the chemical reaction, while the lower frequency ultrasonic generates a relatively stronger shock wave, that can cause a cracking effect (Zhang et al. 2008). It is generally observed that when the ultrasonic frequency is at $20 \mathrm{kHz} \sim 41 \mathrm{kHz}$, the cracking effect in the sludge is the most effective, and the sludge particle size is significantly reduced. During the ultrasonic pretreatment of the sludge, the SCOD dissolution rate enhances with the increasing action time and power density. However, when the action time of the sludge is more than $45 \mathrm{~min}$ or the power is higher than $0.8 \mathrm{~W} / \mathrm{mL}$, the effect begins to weaken (Huan et al. 2009).

When alkali and ultrasonic pre-treat the sludge individually, the upper limit of SCOD/TCOD is $50 \%$. When alkali treatment is first followed by ultrasonic treatment, SCOD/TCOD improves to $70 \%$ (Kim et al. 2010). Alkali pretreatment has the vital role on the subsequent ultrasonic pretreatment efficiency of the sludge, and adding alkaline makes soluble cell metabolic product in the supernatant, and the ultrasonic destroys some of the matters (Ni et al. 2009). However, it will not fundamentally change the compositions and chemical structures of the organic matters in the sludge supernatant (Chen et al. 2003, Wang et al. 2019). The above studies on the pretreatment technologies are all based on the high organic matter sludge as the research object. There are few reports on the enhanced pretreatment of the low organic matter sludge.
Aimed at the problem of the low anaerobic digestion performance of the low organic matter sludge, this study proposes alkali-ultrasonic pretreatment technology by investigating the low organic matter sludge in an urban sewage plant as the research object. Through setting the control group (without pretreatment, alkali treatment, ultrasonic treatment, ultrasonic-alkali stepwise treatment, alkali-ultrasonic stepwise treatment), that investigates the alkali-ultrasonic pretreatment efficiency in the low organic matter sludge, adopts the three-dimensional fluorescence to analyse the dissolvable organic matter in the low organic matter sludge. At the same time, it studies the anaerobic digestion efficiency of the sludge before and after the synchronous alkali-ultrasonic pretreatment, furthermore, uses the $16 \mathrm{~S}$ rRNA high-throughput sequencing technology to explore the influence of the anaerobic digestion of the sludge on the microbial population in the system. The study will open a new way to improve the anaerobic digestion efficiency of the low organic matter sludge.

\section{MATERIALS AND METHODS}

Experimental sludge quality: The experimental sludge was taken from the residual sludge in the second sedimentation tank of a municipal sewage plant. The characteristics of raw sludge are given in Table 1.

3D-EEM and FRI technology: The organic matters can be divided into five parts (Table 2 ) by using the 3D-EEM (Excitation-Emission Matrix) and FRI (Fluorescence Regional Integration) technologies according to the difference of the excited emission wavelengths. The biological acceptability and biodegradability of the matters in the Fluorescence Area I and II are outstanding. The matters in Fluorescence Area III and V usually have poorer biological acceptability and biodegradability. And the matters in Fluorescence Area IV are the microbial metabolic by-products usually, protein complexes, which generally have positive effects on biodegradability (Meng et al. 2011). Therefore, the contents of the organic matters with better biodegradability in the sludge DOM can be reflected in Area I, II and IV, and the contents of the organic matters with the worse biodegradability in the sludge supernatant can be reflected in Area III and V.

Table 1: Experimental sludge quality.

\begin{tabular}{|llll|}
\hline Index & Concentration & Index & Concentration \\
\hline $\mathrm{pH}$ & $7.61 \pm 0.2$ & Soluble protein $(\mathrm{mg} / \mathrm{L})$ & $40.28 \pm 3.6$ \\
$\mathrm{TSS}(\mathrm{g} / \mathrm{L})$ & $26.22 \pm 3.5$ & Soluble polysaccharide $(\mathrm{mg} / \mathrm{L})$ & $7.54 \pm 0.2$ \\
$\mathrm{VSS}(\mathrm{g} / \mathrm{L})$ & $6.06 \pm 4.4$ & VFAs $(\mathrm{mg} / \mathrm{L})$ & $0.08 \pm 0.003$ \\
$\mathrm{VSS} / \mathrm{TSS}(\%)$ & $23.11 \pm 5.6$ & DNA $(\mathrm{mg} / \mathrm{L})$ & $2.22 \pm 0.2$ \\
$\mathrm{SCOD}(\mathrm{mg} / \mathrm{L})$ & $242.46 \pm 12.6$ & Ammonia nitrogen $(\mathrm{mg} / \mathrm{L})$ & $39.15 \pm 1.7$ \\
$\mathrm{TCOD}(\mathrm{mg} / \mathrm{L})$ & $16767.00 \pm 32.7$ & Phosphate $(\mathrm{mg} / \mathrm{L})$ & $1.53 \pm 0.2$ \\
\hline
\end{tabular}


Table 2: Ex/Em wavelengths of fluorescence region of liquid-phase organic matter after different alkali and ultrasonic pretreatment s of the sludge.

\begin{tabular}{|lll|}
\hline Area number & Typical matter & Ex/Em wavelengths \\
\hline I & Tyrosine-protein & $200 \mathrm{~nm} \sim 250 \mathrm{~nm} / 200 \mathrm{~nm} \sim 330 \mathrm{~nm}$ \\
II & Tryptophan-protein & $200 \mathrm{~nm} \sim 250 \mathrm{~nm} / 330 \mathrm{~nm} \sim 380 \mathrm{~nm}$ \\
III & Fulvic acid-organic matter & $200 \mathrm{~nm} \sim 250 \mathrm{~nm} / 380 \mathrm{~nm} \sim 500 \mathrm{~nm}$ \\
IV & Soluble microbial by-products & $250 \mathrm{~nm} \sim 280 \mathrm{~nm} / 200 \mathrm{~nm} \sim 380 \mathrm{~nm}$ \\
V & Humic acid-organic matter & $250 \mathrm{~nm} \sim 400 \mathrm{~nm} / 380 \mathrm{~nm} \sim 500 \mathrm{~nm}$ \\
\hline
\end{tabular}

16S rDNA high-throughput sequencing: 1) DNA extraction. An appropriate amount of the sludge mixture was taken and centrifuged at a high speed $5000 \mathrm{r} / \mathrm{min}, 4^{\circ} \mathrm{C}$ for $5 \mathrm{~min}$. The centrifuged sludge was stored in a refrigerator at $-20^{\circ} \mathrm{C}$ for DNA extraction. Genome DNA of the sludge samples is extracted by using Bead Beater and three times repeated freeze-thaw method in boiling water and liquid nitrogen (Wang et al. 2018). After the genome DNA extraction, the extracted genome DNA is detected by $1 \%$ agarose gel electrophoresis. 2) Construction of $16 \mathrm{~S}$ rDNA gene bank.

The V1-V3 Areas of the 16S rDNA gene are amplified by using bacterial capture primers 27F (5'-AGAGTTTGATCMTGGCTCAG-3') and 533R(5'-TTACCGCGGCTGCTGGCAC-3'). The different samples are distinguished by adding labels. Amplification is performed on GeneAmp®9700 (ABI) PCR instrument. The loading amount is $20 \mu \mathrm{L}$, including $0.4 \mathrm{M}$ forward and reverse primers, $1 \mu \mathrm{L}$ DNA template, 250 nM dNTP and $1 \times$ FastPfu Buffer. PCR operation conditions are as follows: electrophoresis at $95^{\circ} \mathrm{C}$ for $2 \mathrm{~min}$, electrophoresis at $95^{\circ} \mathrm{C}$ for the $30 \mathrm{~s}$, and full operation for 25 times. Renaturation at $55^{\circ} \mathrm{C}$ for the $30 \mathrm{~s}$, extension at $72^{\circ} \mathrm{C}$ for $30 \mathrm{~s}$. All samples were carried out following the formal test conditions, with 3 replicates for each sample. The PCR products were detected and quantified by using the QuantiFluor ${ }^{\mathrm{TM}_{-} \mathrm{ST}}$ blue fluorescence quantification system (Promega Company). After adjusting the sequence to an appropriate level, PCR amplification products were sequenced by using standard Illumina platform. Mothur and QIIME programs were used to aggregate valid sequences with the same classification.

The particle size distribution of the sludge: The Mastersizer 2000 laser particle size analyser was used to determine the particle size distribution of the sludge. The parameters of the instrument were as follows: the matter measurement range $0.02-2000 \mathrm{um}$, the recurrence rate $>0.5 \%$, the accuracy rate $>1 \%$, the data collection speed 1000 times/s. The measurement of a sample can be completed every $15 \mathrm{~s}$. The instrument can calculate the cumulative volume fraction and the average particle size of the sample automatically.

Study on efficiency of the synchronous alkali-ultrasonic pretreatment of the low organic matter sludge: Parallel experiments (set control groups) were used to investigate the efficiency of the alkali-ultrasonic synchronous pretreatment
( $\mathrm{pH}=10$, ultrasonic frequency $28 \mathrm{kH}$, power density $0.4 \mathrm{~W} /$ $\mathrm{mL}$, contact reaction time $30 \mathrm{~min}$ ) of the low organic matter sludge, and 5 control groups were set in parallel at the same time. Control group 1: without pretreatment; Control group 2: alkali treatment $(\mathrm{pH}=10$, reaction time $30 \mathrm{~min})$; Control group 3: ultrasonic treatment (ultrasonic frequency $28 \mathrm{kH}$, power density $0.4 \mathrm{~W} / \mathrm{mL}$, contact time $30 \mathrm{~min}$ ); Control group 4: ultrasonic-alkali stepwise treatment (ultrasonic frequency $28 \mathrm{kH}$, power density $0.4 \mathrm{~W} / \mathrm{mL}$, contact time $15 \mathrm{~min} ; \mathrm{pH}=10$, reaction time $15 \mathrm{~min}$ ); Control group 5: alkali-ultrasonic stepwise treatment $(\mathrm{pH}=10$, reaction time $15 \mathrm{~min}$; ultrasonic frequency $28 \mathrm{kH}$, power density $0.4 \mathrm{~W} / \mathrm{mL}$, contact time $15 \mathrm{~min})$. The supernatant SCOD, soluble protein, soluble polysaccharide, VFAs, DNA and other indicators of the sludge before and after pretreatment were tested to characterize the efficiency of the pretreatment.

Study on the organic matter conversion rules in the synchronous alkali-ultrasonic pretreatment system of the low organic matter sludge: The liquid phase organic matter species of the synchronous alkali-ultrasonic pretreatment system of the low organic matter sludge and the control group (without pretreatment) were tested by the three-dimensional fluorescence spectroscopy technology to analyse the organic matter conversion rules. Besides, the laser particle size analyser was used to test the indexes such as the particle size and the distribution of the sludge, of the synchronous alkali-ultrasonic pretreatment system of the low organic matter sludge and the control group (without pretreatment).

Study on the influence of the synchronous alkaliultrasonic pretreatment of the low organic matter sludge on the anaerobic digestion system and the microbial population: The treatment efficiency of the anaerobic digestion system (SRT 30d) of the synchronous alkaliultrasonic pretreatment of the low organic matter sludge ( $\mathrm{pH}=10$, ultrasonic frequency $28 \mathrm{kHz}$, power density 0.4 $\mathrm{W} / \mathrm{mL}$, contact reaction time $15 \mathrm{~min}$ ) and the control group (without pretreatment without pretreatment) is investigated by the parallel experiments. The influence of $16 \mathrm{~S}$ rRNA high-throughput sequencing on the microbial population is analysed by using the structure of the microbial population and the functional bacteria of archaea group in the synchronous alkali-ultrasonic pretreatment system of the 
low organic matter sludge and the control group (without pretreatment).

\section{RESULTS AND DISCUSSION}

Study on the efficiency of the synchronous alkali-ultrasonic pretreatment of the low organic matter sludge: The experimental results of the influences of the alkali and ultrasonic treatment methods on the pretreatment efficiency of the low organic matter sludge are shown in Fig. 1.

As presented in Fig. 1, the alkaline and ultrasonic treatment methods have a significant influence on the pretreatment efficiency of the low organic matter sludge. After pretreatment with synchronous alkali-ultrasonic treatment, the SCOD in the sludge supernatant increases to $7496 \mathrm{mg} / \mathrm{L}$, which is enhanced by $15.44,10.36,1.05,0.91$ and 0.59 times compared with the control groups (without pretreatment 456 $\mathrm{mg} / \mathrm{L}$, alkaline treatment $660 \mathrm{mg} / \mathrm{L}$, ultrasonic treatment 3644 $\mathrm{mg} / \mathrm{L}$, ultrasound-alkali stepwise treatment $3916 \mathrm{mg} / \mathrm{L}$ and alkali-ultrasonic stepwise treatment $4700 \mathrm{mg} / \mathrm{L}$ ). The VFAs of the sludge supernatant increase to $505.14 \mathrm{mg} / \mathrm{L}$, which is $59.64,14.64,2.03,1.31$ and 0.61 times higher than those of the control groups (without pretreatment $8.33 \mathrm{mg} / \mathrm{L}$, alkali treatment $32.30 \mathrm{mg} / \mathrm{L}$, ultrasonic treatment $166.69 \mathrm{mg} / \mathrm{L}$, ultrasound-alkali stepwise treatment $218.60 \mathrm{mg} / \mathrm{L}$ and alkaliultrasonic stepwise treatment $314.49 \mathrm{mg} / \mathrm{L}$ ). The soluble proteins increase by $23.25,9.44,1.10,0.79$ and 0.39 times respectively, and the soluble polysaccharides elevate by $14.13,4.81,0.33,0.17$ and 0.11 times respectively. The order of processing efficiency is as follows: synchronous alkaliultrasonic treatment $>$ ultrasound-alkali stepwise treatment $>$ alkali-ultrasonic stepwise treatment $>$ ultrasonic treatment $>$ alkali treatment. The synchronous alkali-ultrasonic treatment system has a strong treatment efficiency.

The sludge can promote the dissolution of EPS and the microbial cytoplasm under the action of alkali (Jang \& Ahn 2013). Low frequency ultrasonic wave can have stronger cavitation effect, which can break the cell wall and promote the transfer of the organic matters from the sludge to the liquid phase to a greater extent (Neis et al. 2000). During the synchronous alkali-ultrasonic action, the addition of alkali makes the flocculation structure of the sludge to become enlarged, so that the cavitation bubbles generated by ultrasonic reaction have a larger reaction area with EPS and microorganisms. And the change of the reaction sequence between ultrasonic and alkali significantly weakens this effect (Ni et al. 2009).

Study on the organic matter conversion rules in the synchronous alkali-ultrasonic pretreatment system of the low organic matter sludge: The liquid phase 3D-EEM spectra and FRI analysis integral results after the low organic matter sludge treated by the different pretreatment systems are shown in Fig. 2.

As presented in Fig. 2, after the low organic matter sludge is pre-treated in different methods, it significantly promotes the dissolution of the easily degraded organic matter in the sludge. The total fluorescence intensity of the sludge supernatant increases to $24.58 \times 107$ (a.u.) after the synchronous alkaliultrasonic pretreatment of the low organic matter sludge, while the control groups are without pretreatment $5.63 \times 107$ (a.u.), alkali pretreatment $10.82 \times 107$ (a.u.), ultrasonic pretreatment $15.41 \times 107$ (a.u.), ultrasound-alkali stepwise pretreatment $21.83 \times 107$ (a.u.), and alkali-ultrasonic stepwise pretreatment $22.19 \times 107$ (a.u.). The fluorescence intensities of the Areas

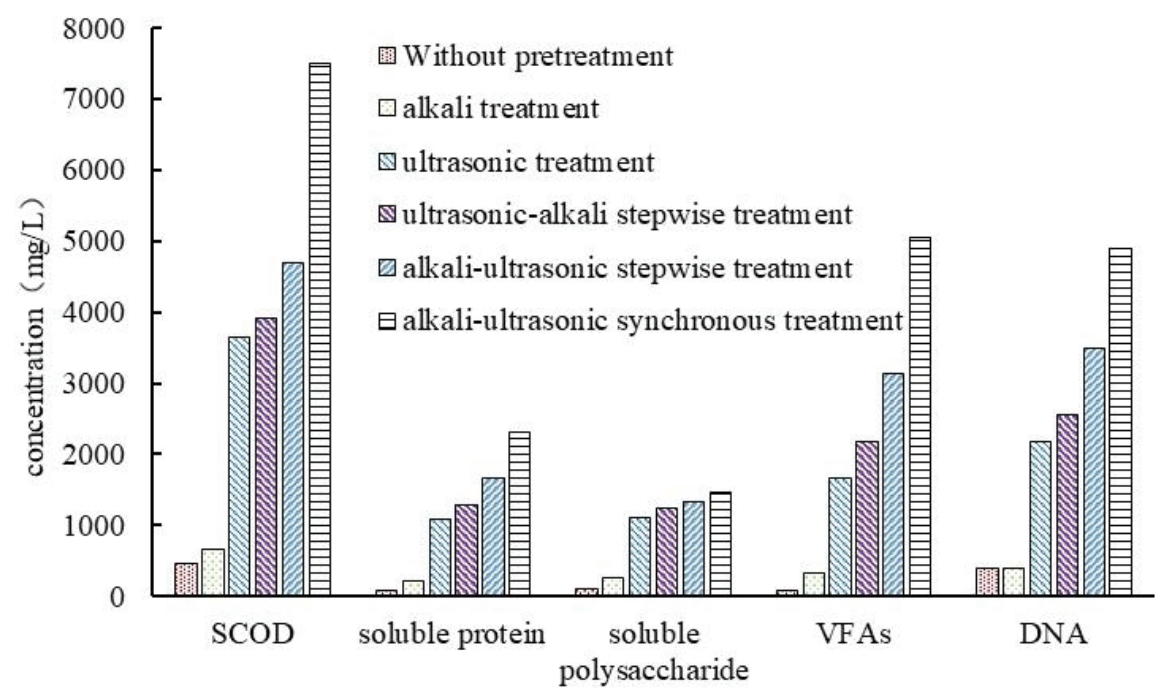

Fig. 1: Influence on the pretreatment efficiency of different alkaline and ultrasonic treatment methods of the sludge. 

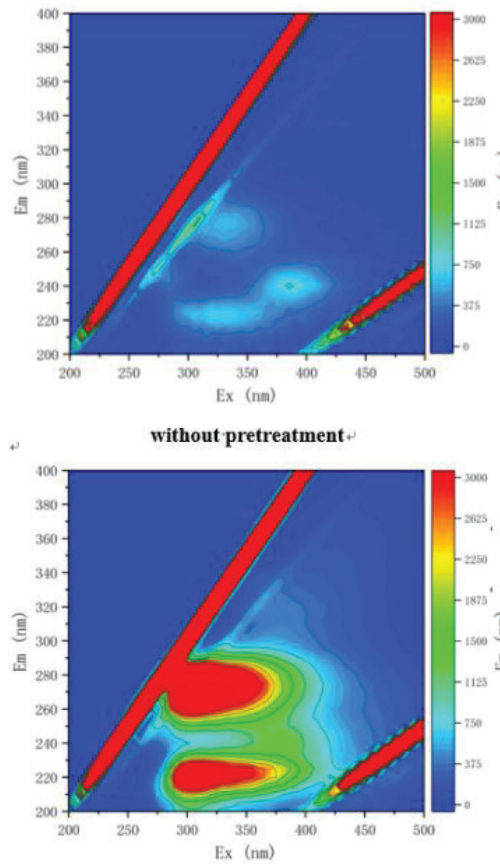

ultrasonic treatment

$$
4
$$

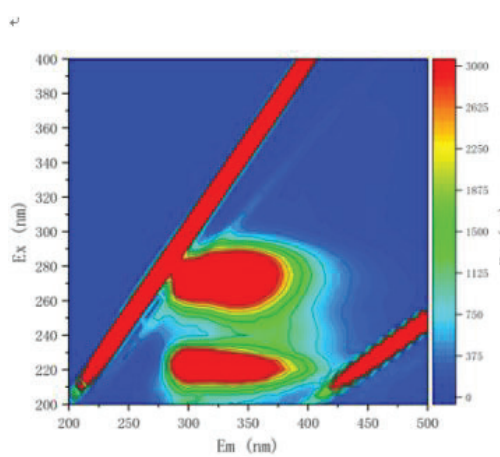

alkali-ultrasonic stepwise treatment

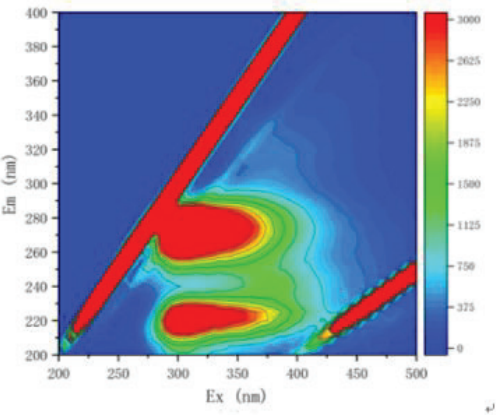

alkali treatment

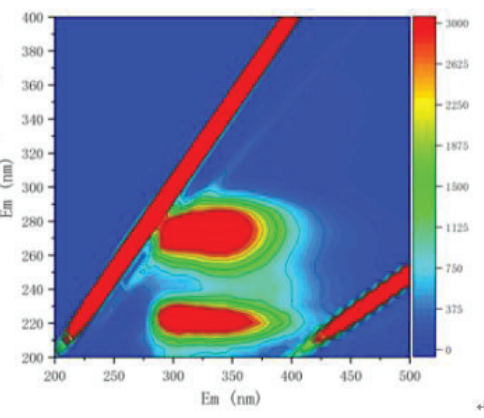

ultrasonic-alkali-stepwise treatment

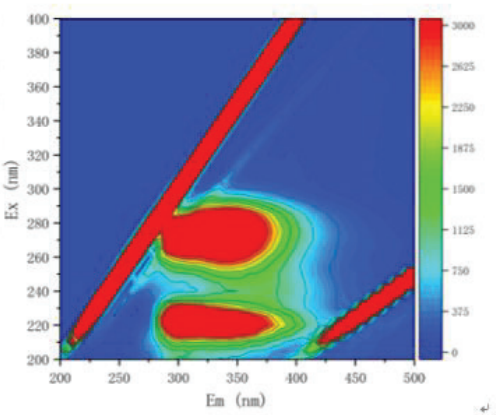

alkali-ultrasonic synchronous treatment .

(a)

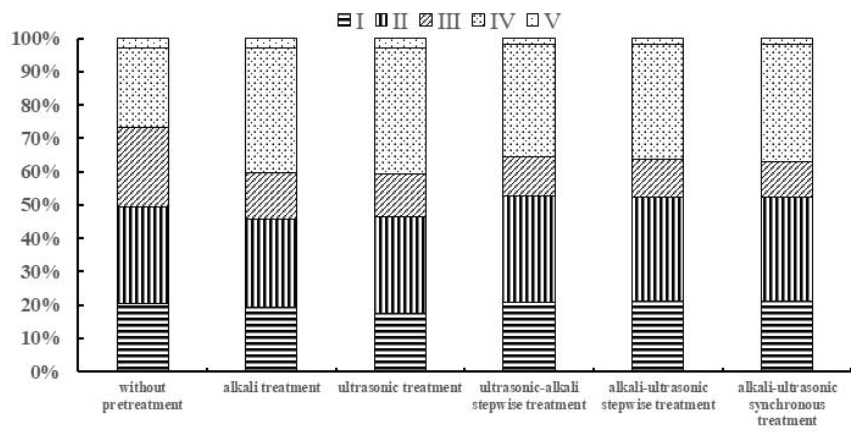

(b)

Fig 2: (a) Liquid phase three-dimensional fluorescence spectra and (b) FRI analysis integral diagram of different sludge pretreatment systems. 
of easily biodegradable matters (Area I, II and IV) (Sun et al. 2016) account for $80.74 \%, 81.12 \%, 86.64 \%, 86.00 \%$ and $87.35 \%$, higher than the control group $(73.34 \%)$ by $10.1 \%$, $10.6 \%, 18.1 \%, 17.3 \%, 19.1 \%$, respectively.

These results show that the actions of alkali and ultrasonic in different methods have not only affected the pretreatment of the sludge flocculation and the breakage of the cell wall to make organic matter dissolute but also promote fulvic acids, quinones, humic acid, other organic matter such as polycyclic aromatic hydrocarbons and other large molecule organic matters to transfer into small molecule organic matters by the alkaline hydrolysis "catalyst" function and the ultrasonic cavitation effect, which have certain modification effect on the soluble organic matters ( $\mathrm{Ni}$ et al. 2009). The organic dissolution and modification effects of the synchronous alkali-ultrasonic pretreatment method are best. The dissolvable organic matters are mainly tyrosine, tryptophan and microbial products and other easily biodegradable organic matters. However, the fluorescence peak types are the same, which indicate that alkali and ultrasonic pretreatment s will not fundamentally change the composition of the organic matters in the sludge supernatant (Chen et al. 2003).

Study on the sludge morphology changes in the synchronous alkali-ultrasonic pretreatment system of the low organic matter sludge: The experimental results of the influence of different pretreatment methods on the particle size distribution of the sludge are given in Table 3 and Fig. 3. Pretreatment has significant influence on the sludge morphology. After the synchronous pretreatment with alkali, ultrasonic and alkaliultrasonic of the sludge, the average particle size of the sludge (D[4,3]) decreases from $80.279 \mu \mathrm{m}$ without pretreatment to $76.858 \mu \mathrm{m}, 36.003 \mu \mathrm{m}$ and $30.241 \mu \mathrm{m}$, which decrease by $\% 55.2, \% 4.3$ and \%62.3 respectively. The addition of alkali makes the negative charge on the surface of the sludge particles
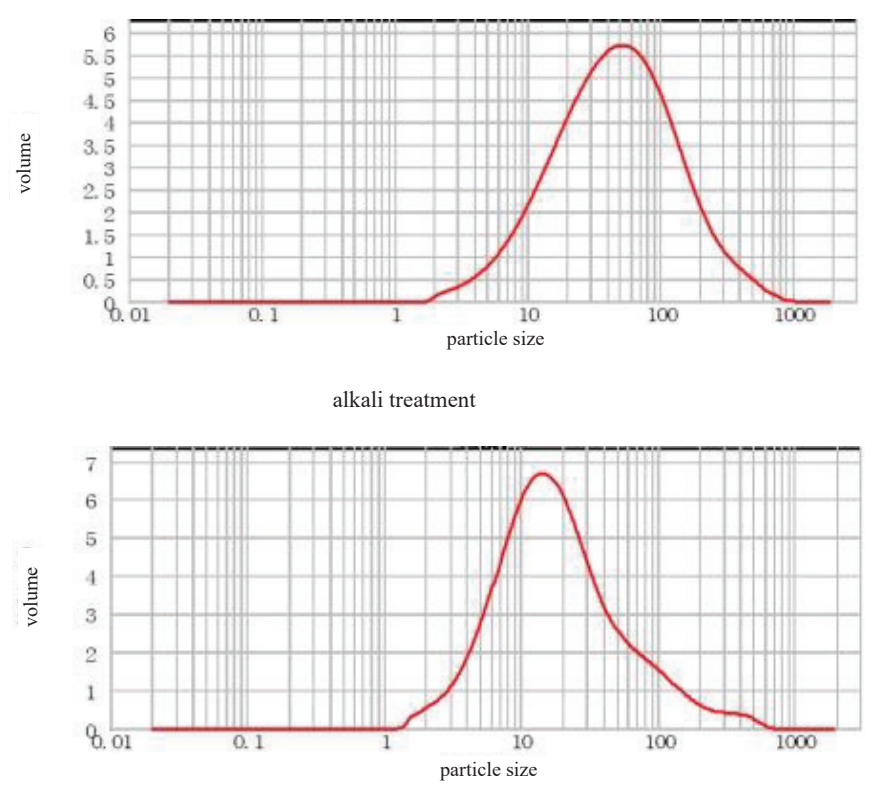

ultrasonic treatment

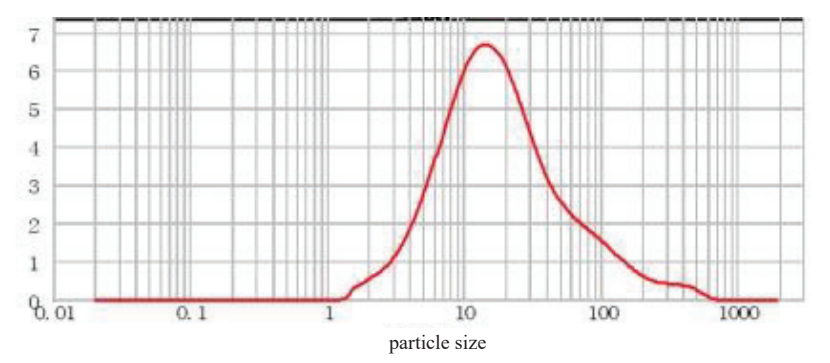

Synchronous alkali-ultrasonic pretreatment

Fig. 3: The sludge particle size distribution change diagram of different alkali and ultrasonic pretreatment methods of the sludge. 


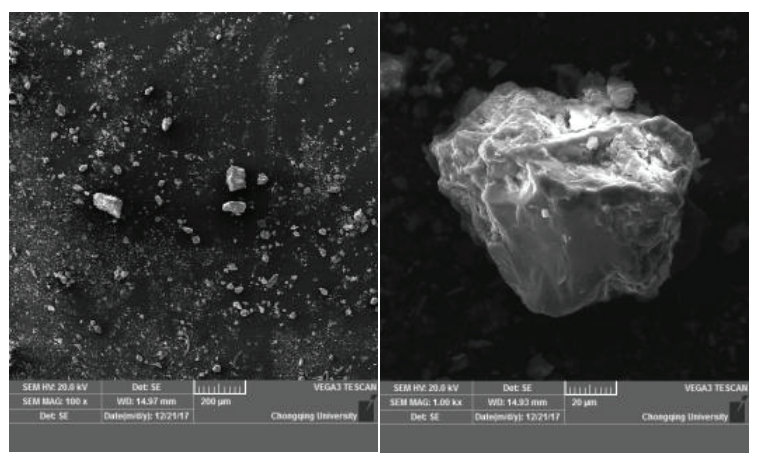

raw sludge

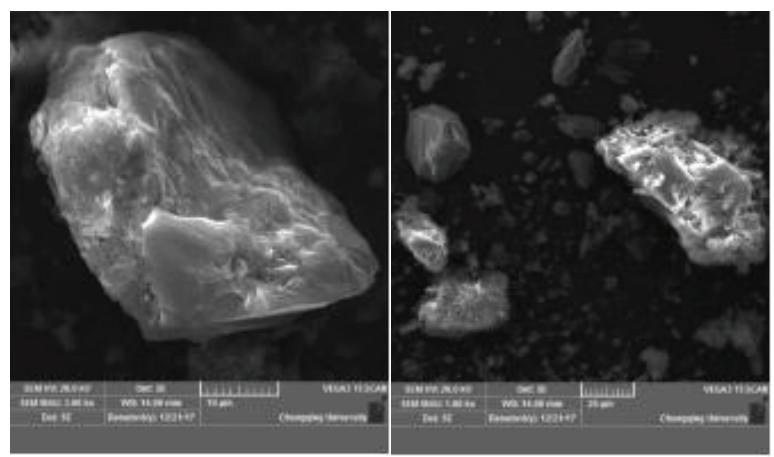

alkali treatment

ultrasonic treatment

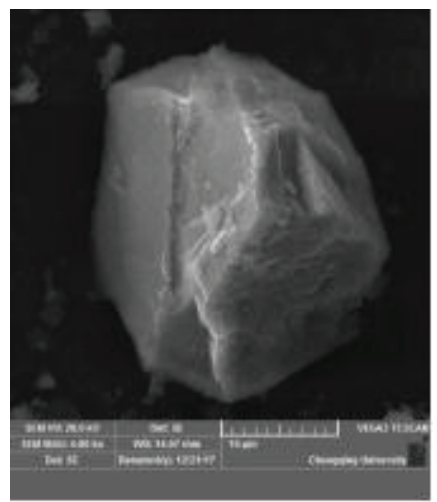

Synchronous alkali-ultrasonic treatment

Fig. 4: SEM diagram before and after treatment of different pretreatment methods of the sludge.

Table 3: Particle size distribution statistics.

\begin{tabular}{|lllll|}
\hline Sample & Control group & Alkali treatment & Ultrasonic treatment & Synchronous alkali-ultrasonic treatment \\
\hline $\mathrm{d}(0.1) / \mu \mathrm{m}$ & 11.45 & 11.228 & 5.375 & 7.151 \\
$\mathrm{~d}(0.5) / \mu \mathrm{m}$ & 47.823 & 46.823 & 16.608 & 17.835 \\
$\mathrm{~d}(0.9) / \mu \mathrm{m}$ & 179.647 & 172.599 & 80.426 & 54.984 \\
$\mathrm{D}[3,2] / \mu \mathrm{m}$ & 26.01 & 25.576 & 11.566 & 13.803 \\
$\mathrm{D}[4,3] / \mu \mathrm{m}$ & 80.279 & 76.858 & 36.003 & 30.241 \\
\hline
\end{tabular}


gradually increase, and the produced electrostatic force makes the extracellular polymer structure widen (Penaud et al. 1999). The cavitation and the shearing actions of the ultrasonic wave on the sludge promote the disintegration of the microbial flocculation. The combined actions greatly improve the dissolution of the large granular sludge and reduce the average particle size of the sludge.

The SEM results of the different pretreatment methods of the sludge are shown in Fig. 4. In the control group (raw sludge), the particle sizes of the sludge are different and the appearance is rough. The improvement effect of the alkali treatment on the surface appearance of the inorganic sand is not obvious. After the ultrasonic treatment, the sludge surface becomes smooth, and a large number of the organic matters in the sludge adhere to the sand and gravel. The ultrasonic wave causes vibration of water molecules, microorganisms and other solutes, which causes the organic matter to be detached from the sand and gravel, making the particle size smaller and the surface become smooth (Dai et al. 2017).

Influence of the synchronous alkali-ultrasonic pretreatment on the anaerobic digestion system efficiency of the low organic matter sludge: The BMP test results of the synchronous alkali-ultrasonic pretreatment of the sludge anaerobic digestion system with low organic matter sludge and the control group (without pretreatment ) are shown in Fig. 5. The gas production effect of the synchronous alkali-ultrasonic pretreatment sludge anaerobic digestion system is significantly improved compared with the raw sludge system without pretreatment. After the synchronous alkali-ultrasonic pretreatment, the SCOD and the VFAs in the sludge supernatant increase from $2040 \mathrm{mg} / \mathrm{L}$ and 305.87 $\mathrm{mg} / \mathrm{L}$ to $10840 \mathrm{mg} / \mathrm{L}$ and $1303.80 \mathrm{mg} / \mathrm{L}$ respectively, and decrease to $808 \mathrm{mg} / \mathrm{L}, 49 \mathrm{mg} / \mathrm{L}, 4090 \mathrm{mg} / \mathrm{L}$ and $51 \mathrm{mg} / \mathrm{L}$ after $30 \mathrm{~d}$ operation. The gas production increases by $58 \%$ from $250 \mathrm{~mL}$ to $396 \mathrm{~mL}$.
Analysis of the microbial population in the anaerobic digestion system of the low organic matter sludge: The $16 \mathrm{~S}$ rRNA high-throughput sequencing results of the sludge samples $\mathrm{S} 1$ in the control group (the raw sludge anaerobic digestion system) and S2 in the experimental group (the synchronous alkali-ultrasonic pretreatment sludge anaerobic digestion system) are provided in Table 4 . According to the analysis results of the biological population OUT, abundance and diversity, the anaerobic digestion system of the sludge in the experimental group gets 44,864 Tags, and the anaerobic digestion system of the control group gets 44,818 Tags. After the pretreatment, the sludge enters the anaerobic digestion system, and its biodiversity (Shannon index) decreases from 5.24 to 5.00 .

The phylum biological population of the anaerobic digestion system of the sludge without pretreatment and after alkali-ultrasonic synchronous pretreatment is shown in Fig. 6 . The 36 species phylum population were detected in the anaerobic digestion system of the unpretreated sludge, among which the abundances of 9 species are higher than $1 \%$, Firmicutes (16.06\%), Bacteroidetes (15.24\%), Actinobacteria (16.13\%), Chloroflexi (16.19\%), Hydrooxidize Bacteria WS6 (13.09\%), Proteobacteria (13.93\%), Synergistetes $(1.15 \%)$, Saccharibacteria $(0.65 \%)$ and Planctomycetes $(1.44 \%)$ respectively. The 32 species phylum populations are detected in the anaerobic digestion system of the sludge after the synchronous alkali-ultrasonic pretreatment. The microbial diversity decreases, among which the abundances of 9 phylum populations are higher than 1\%, Firmicutes (35.98\%), Bacteroidetes (13.34\%), Actinobacteria (11.48\%), Chloroflexi $(10.51 \%)$, Hydrooxidize Bacteria WS6 (6.97\%), Proteobacteria (4.64\%), Synergistetes (8.22\%), Saccharibacteria (1.60\%) and Planctomycetes (1.06\%).

The abundances of Firmicutes and Synergistetes in the experimental group increase by 1.24 times and 6.15 times re-

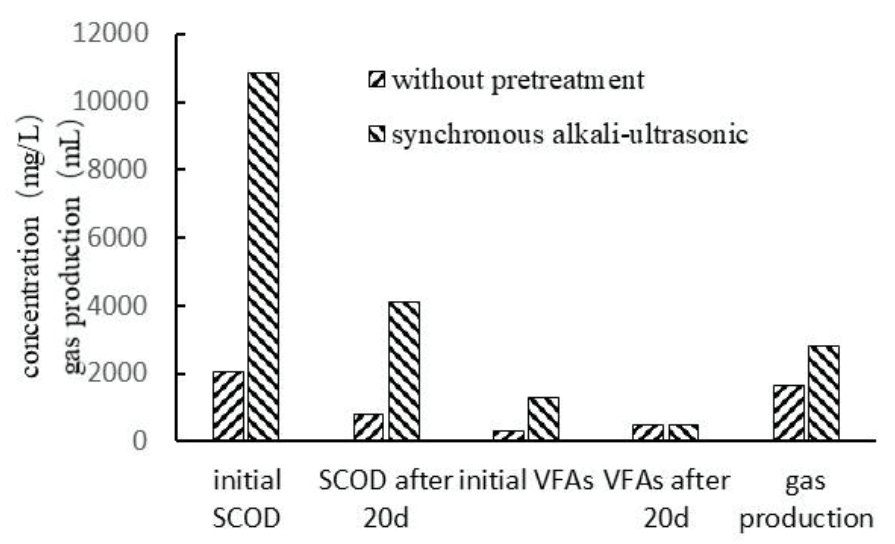

Fig. 5: Influence on the anaerobic digestive system efficiency of synchronous alkali-ultrasonic pretreatment of the low organic matter sludge. 
spectively compared with those of the control group. Under the Firmicutes, the microbial genera can degrade the complex carbohydrates including cellulose into the small molecules such as acetic acid and butyric acid (Zhang \& Lynd 2005). Synergistetes usually grow interactively with ethanotropic methanogens in the anaerobic digestion system to enable high-efficient operation of the anaerobic digestive system (Ahring 2003).

The genus microbial population of the anaerobic digestion system of the raw sludge and the sludge after the synchronous alkali-ultrasonic pretreatment are shown in Fig. 7. The dominant functional bacterial taxa in the system mainly include vadinHA17, Peptoclostridium, Peptostreptococcaceae, Tissierella, Syntrophomonas, Synergistaceae and Aminobacterium. Among them, vadinHA17, Peptoclostridium, Peptostreptococcaceae and Tissierella have the functions of producing acetic acid, propionic acid, butyric acid and other short-chain fatty acids (Ariesyady et al. 2007). The abundances in the test group are $8.91 \%, 6.32 \%, 3.37 \%$ and $3.23 \%$ respectively, which are largely improved compared with those in the control group $(8.28 \%, 0.1 \%, 5.48 \%$ and $0.1 \%)$. The Syntrophomonas and Synergistaceae bacterial genera have the function of transforming fatty acids and other small molecular matters into acetic acid, hydrogen and carbon dioxide (Iino et al. 2007). The abundances of the experimental group are $3.08 \%$ and $3.06 \%$ respectively, which are significantly improved compared with those in the control group $(1.22 \%$ and $0.1 \%$ ). Aminobacterium has the function of amino acid degradation. The abundance of the experimental group $(3.84 \%)$ is significantly improved compared with that of the control group $(0.1 \%)$.

Analysis of the archaea population in the anaerobic digestion system: The results of the archaea OTU, abundance and diversity samples sequencing analysis are given in Table 5. The control group gets 32,288 Tags and the experimental group gets 42,585 Tags. After the synchronous alkali-ultrasonic pretreatment, the biodiversity (Shannon index) of the sludge in the anaerobic digestion system decreases from 3.39 to 2.32 .

Table 4: Results of OUT, abundance and diversity samples sequencing depth analysis.

\begin{tabular}{|c|c|c|c|c|c|}
\hline Sample ID & Sequences & Ace & Chao & Shannon & Coverage \\
\hline $\begin{array}{l}\text { Control group } \\
\text { (Samples of the system without pretreatment ) (S1) }\end{array}$ & 44818 & 757 & 759 & 5.24 & 0.9994 \\
\hline $\begin{array}{l}\text { Experimental group } \\
\text { (Synchronous alkali-ultrasonic pretreatment of the sludge anaerobic digestion system } \\
\text { samples) (S2) }\end{array}$ & 44864 & 714 & 737 & 5 & 0.99909 \\
\hline
\end{tabular}

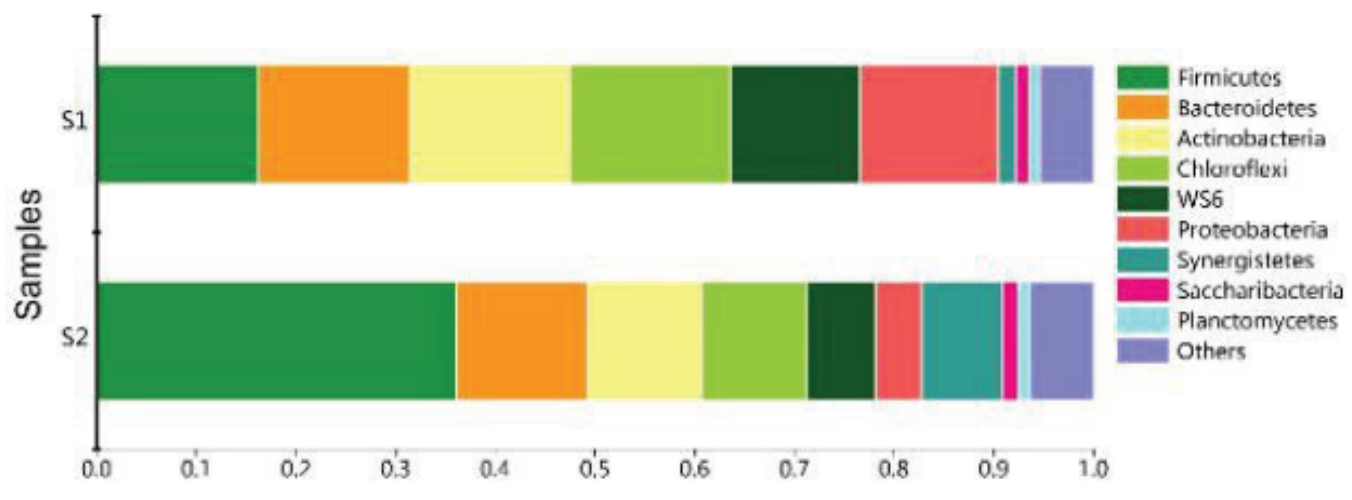

Fig. 6: Histogram of the phylum biological population in the anaerobic digestion system of the raw sludge and the sludge with the synchronous alkaliultrasonic pretreatment.

Table 5: Results of archaea population OTU, abundance and diversity samples sequencing depth analysis.

\begin{tabular}{|c|c|c|c|c|c|}
\hline Sample ID & Sequences & Ace & Chao & Shannon & Coverage \\
\hline $\begin{array}{l}\text { Control group } \\
\text { (Samples of anaerobic digestion system of raw sludge) (S1) }\end{array}$ & 42585 & 320 & 320 & 3.39 & 0.99976 \\
\hline $\begin{array}{l}\text { Experimental group } \\
\text { (Samples of sludge anaerobic digestion system after synchronous alkali-ultrasonic } \\
\text { pretreatment })(\mathrm{S} 2)\end{array}$ & 32288 & 227 & 216 & 2.32 & 0.99854 \\
\hline
\end{tabular}




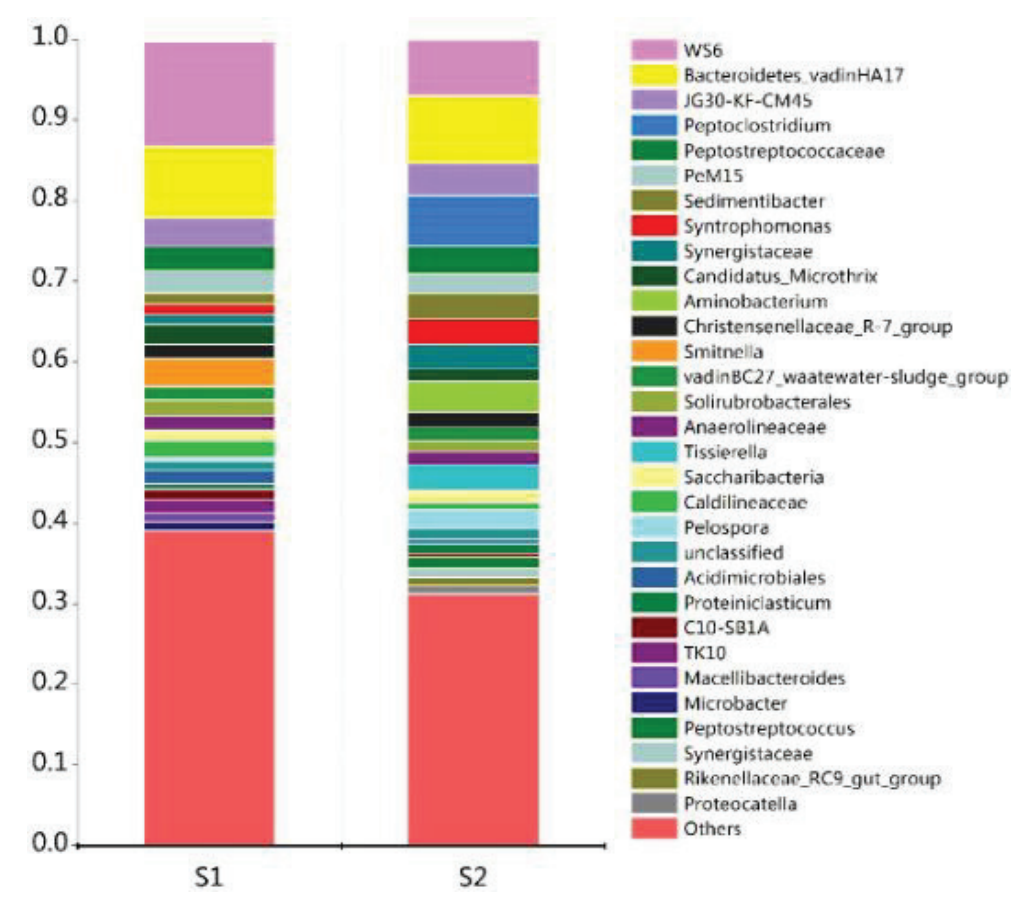

Fig. 7: Histogram of the genus biological population in the anaerobic digestion system of the raw sludge and the sludge with the synchronous alkaliultrasonic pretreatment.

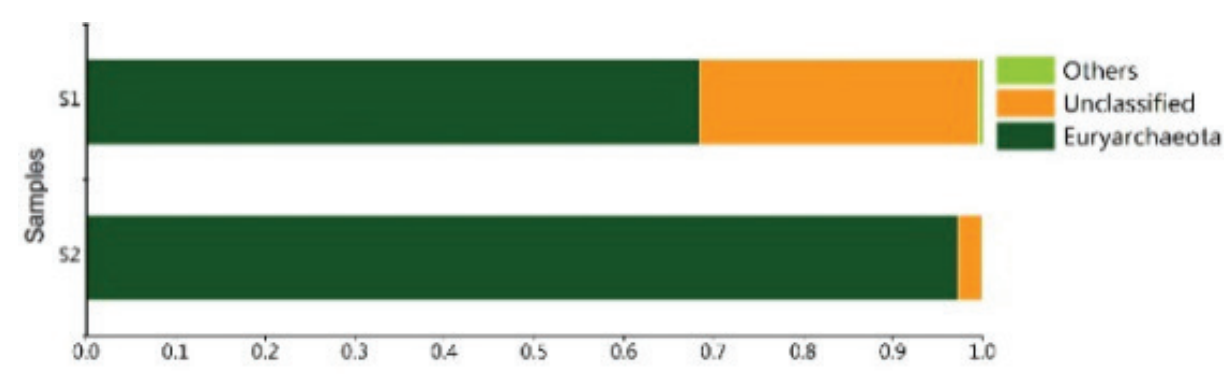

Fig. 8: Histogram of the phylum archaea populations in the anaerobic digestion system of the raw sludge and the sludge with the synchronous alkaliultrasonic pretreatment.

The results of the phylum analysis of the system archaea organisms in the control group and the experimental group are shown in Fig. 8. The abundance of Euryarchaeota in the experimental group is $97.25 \%$, an increase of $42 \%$ compared with $68.40 \%$ in the control group. Methanogens mainly belong to the microbial bacteria of Eurycloea, which is beneficial to improving the efficiency of the anaerobic digestion system.

The genera and species of archaea in the control group and the experimental group are shown in Fig. 9. The dominant functional genera in the experimental group are mainly Methanosaeta $(70.33 \%)$, Unclassified (2.74\%), Methanosarcina (15.49\%), Methanobacterium (5.31\%), Methanospirillum (2.18\%), ARC26 (1.04\%) and Methanobrevibacter (1.62\%). Among them, Methanosaeta and Methanosarcina are acetotrophic methanogens (Sun et al. 2008), whose abundances are higher than those of the control group $(54.5 \%, 0.22 \%)$. However, the abundances of $\mathrm{H}_{2}+\mathrm{CO}_{2}$ nutritive methanogens, such as Methanobacterium and Methanospirillum, have little changes compared with those of the control group, which may be related to the improvement of the abundances of the acetic acid bacteria in the hydrolytic acidification process.

\section{CONCLUSIONS}

After the synchronous alkali-ultrasonic pretreatment of the low organic matter sludge, the dissolution of the large-particle sludge is enhanced. The average particle size of the sludge is 
reduced. The dissolution and modification effects on the sludge organic matter are best. After the pretreatment, the concentrations of supernatant SCOD and VFAs increase by 11.36 times and 59.64 times respectively compared with those of the unpretreated system. The dissolved organic matters are mainly the biodegradable organic matters such as tyrosine, tryptophan and microbial products. The biodegradable matters are $19.1 \%$ higher than those of the unpretreated system, and their gas production is $58 \%$ higher than that of the unpretreated system.

The biological diversity of the anaerobic digestion system and the diversity of archaea are significantly reduced by the synchronous alkali-ultrasonic pretreatment of the low organic matter sludge, among which the abundances of Firmicutes and Synergistetes increase by 1.24 times and 6.15 times respectively compared with those of the control group. The dominant functional bacteria, such as vadinHA17, Peptoclostridium, Peptostreptococcaceae, Tissierella, Syntrophomonas, Synergistaceae, Aminobacterium, increase significantly. The dominant functional bacteria of the system archaea biological population genera mainly include Methanosaeta (70.33\%), Unclassified (2.74\%), Methanosarcina (15.49\%), Methanobacterium (5.31\%), Methanospirillum (2.18\%), ARC26 (1.04\%) and Methanobrevibacter (1.62\%). The abundance of the functional bacteria is significantly higher than that of the control group.

\section{REFERENCES}

Ahring, B.K. 2003. Perspectives for anaerobic digestion. Adv. Biochem. Eng. Biotechnol., 81: 1-30.

Ariesyady, H.D., Ito, T. and Okabe, S. 2007. Functional bacterial and archaeal community structures of major trophic groups in a full-scale anaerobic sludge digester. Water Res., 41(7): 1554-1568.

Carrere, H., Dumas, C., Battimelli, A., Batstone, D.J., Delgenes, J.P., Steyer, J.P. and Ferrer, I. 2010. Pretreatment methods to improve sludge anaerobic degradability: A review. J. Hazard. Mater., 183(1-3): 1-15.

Chen, W., Westerhoff, P., Leenheer, J.A. and Booksh, K. 2003. Fluorescence excitation-emission matrix regional integration to quantify spectra for dissolved organic matter. Environ. Sci. Technol., 37(24): 5701-5710.

Dai, X., Xu, Y. and Dong, B. 2017. Effect of the micron-sized silica particles (MSSP) on biogas conversion of sewage sludge. Water Res., 115: 220-228.

Delgèns, J.P., Penaud, V., Torrijos, M. and Moletta, R. 2000. Investigations on the changes in anaerobic biodegradability and biotoxicity of an industrial microbial biomass induced by a thermochemical pretreatment. Water Sci. Technol., 41(3): 137-144.

He, P.J., Lü, F., Zhang, H., Shao, L.M. and Lee, D.J. 2007. Sewage sludge in China: Challenges toward a sustainable future. Water Practice and
Technology, 2(4): wpt2007083. doi10.2166/wpt.2007.083

Huan, L., Yiying, J., Mahar, R.B., Zhiyu, W. and Yongfeng, N. 2009. Effects of ultrasonic disintegration on sludge microbial activity and dewaterability. J. Hazard. Mater., 161(2-3): 1421-1426.

Iino, T., Mori, K., Tanaka, K., Suzuki, K. and Harayama, S. 2007. Oscillibacter valericigenes gen. nov., sp. nov., a valerate-producing anaerobic bacterium isolated from the alimentary canal of a Japanese corbicula clam. Int. J. Syst. Evol. Microbiol., 57(Pt 8): 1840-1845.

Jang, J.H. and Ahn, J.H. 2013. Effect of microwave pretreatment in presence of $\mathrm{NaOH}$ on mesophilic anaerobic digestion of thickened waste activated sludge. Bioresour. Technol., 131: 437-442.

Kim, D.H., Jeong, E., Oh, S.E. and Shin, H.S. 2010. Combined (alkaline+ultrasonic) pretreatment effect on sewage sludge disintegration. Water Res., 44(10): 3093-3100.

Li, H., Li, C., Liu, W. and Zou, S. 2012. Optimized alkaline pretreatment of sludge before anaerobic digestion. Bioresour. Technol., 123: 189-194.

Meng, F., Zhou, Z., Ni, B.J., Zheng, X., Huang, G., Jia, X., Li, S., Xiong, Y. and Kraume, M. 2011. Characterization of the size-fractionated biomacromolecules: tracking their role and fate in a membrane bioreactor. Water Res., 45(15): 4661-4671.

Neis, U., Nickel, K. and Tiehm, A. 2000. Enhancement of anaerobic sludge digestion by ultrasonic disintegration. Water Sci. Technol., 42(9): 73-80.

Ni, B.J., Fang, F., Xie, W.M., Sun, M., Sheng, G.P., Li, W.H. and Yu, H.Q. 2009. Characterization of extracellular polymeric substances produced by mixed microorganisms in activated sludge with gel-permeating chromatography, excitation-emission matrix fluorescence spectroscopy measurement and kinetic modeling. Water Res., 43(5): 1350-1358.

Penaud, V., Delgenès, J.P. and Moletta, R. 1999. Thermo-chemical pretreatment of a microbial biomass: influence of sodium hydroxide addition on solubilization and anaerobic biodegradability. Enzyme and Microbial Technology, 25(3-5): 258-263.

Sun, J., Guo, L., Li, Q., Zhao, Y., Gao, M., She, Z. and Wang, G. 2016. Structural and functional properties of organic matters in extracellular polymeric substances (EPS) and dissolved organic matters (DOM) after heat pretreatment with waste sludge. Bioresour. Technol., 219: 614-623.

Sun, Y., Zuo, J., Chen, L. and Wang, Y. 2008. Eubacteria and Archaea community of simultaneous methanogenesis and denitrification granular sludge. J. Environ. Sci. (China), 20(5): 626-631.

Wang, Y., Gong, B., Lin, Z., Wang, J., Zhang, J. and Zhou, J. 2018. Robustness and microbial consortia succession of simultaneous partial nitrification, ANAMMOX and denitrification (SNAD) process for mature landfill leachate treatment under low temperature. Biochem. Eng. J., 132: 112-121.

Wang, Y., Lin, Z., He, L., Huang, W., Zhou, J. and He, Q. 2019. Simultaneous partial nitrification, anammox and denitrification (SNAD) process for nitrogen and refractory organic compounds removal from mature landfill leachate: Performance and metagenome-based microbial ecology. Bioresour. Technol., 294: 122166.

Zhang, G., Zhang, P., Gao, J. and Chen, Y. 2008. Using acoustic cavitation to improve the bio-activity of activated sludge. Bioresour. Technol., 99(5): 1497-502.

Zhang, Y.H. and Lynd, L.R. 2005. Cellulose utilization by Clostridium thermocellum: Bioenergetics and hydrolysis product assimilation. Proc. Natl. Acad. Sci., U.S.A., 102(20): 7321-7325. 